\title{
Alcohol use and addiction services in Ukraine
}

\author{
Andriy V. Samokhvalov $\mathrm{PhD}^{1}$ Valerii S. Pidkorytov $\mathrm{PhD}^{2}{ }^{2}$ Igor V. Linskiy $\mathrm{PhD},{ }^{2}$ \\ Oleksandr I. Minko PhD, ${ }^{2}$ Oleksii O. Minko MD, Jürgen Rehm PhD ${ }^{1}$ and \\ Svetlana Popova $\mathrm{PhD}^{3}$
}

${ }^{1}$ Public Health and Regulatory Policies, Centre for Addiction and Mental Health, Toronto, Canada; ${ }^{2}$ Institute of Neurology, Psychiatry and Narcology of the Academy of Medical Sciences of Ukraine, Kharkiv, Ukraine; ${ }^{3}$ Public Health and Regulatory Policies, Centre for Addiction and Mental Health, 33 Russell Street, Room T510, Toronto, Ontario, Canada M5S 2S1, email lana_popova@camh.net

U kraine, with a population of 46.2 million, is the second largest country in Europe, with an area of $603700 \mathrm{~km}^{2}$. It is still recovering from the collapse of the Soviet Union in 1991, following the Soviet stagnation era (since the mid-1960s) and perestroika (from 1986), as well as the 1998 Russian financial crisis and Ukraine's 2004 Orange Revolution. These events have resulted in high levels of socio-economic disparity, political instability and a degraded healthcare infrastructure. These issues, in addition to traditionally high levels of alcohol consumption, have made binge drinking and alcoholism, among other addictions, major problems in Ukrainian society (Voloshin et al, 2003).

\section{Rates of disorder}

According to estimates, the average annual recorded consumption of the equivalent of pure alcohol per capita among the population aged 15 and over is about 5 litres; however, unrecorded per capita alcohol consumption for this population is double that figure (10.5 litres) and is the highest among European countries (Popova et al, 2007); the overall alcohol consumption in Ukraine ranks among the top 5\% of all countries globally (see http://www.who.int/globalatlas/ default.asp). The preferred beverage in Ukraine is spirits. The Ukraine 2002 World Mental Health Survey revealed that 'lifetime alcohol use' was reported by $97 \%$ of the respondents (total sample size $=1719$ ). That was the highest consumption in the World Health Organization's Mental Health Survey of 17 countries (WHO World Mental Health Survey Consortium, 2004). Similarly, Degenhardt et al (2008) reported that more than $39 \%$ of young adults in Ukraine have started to drink by age 15 and almost all (99\%) by age 21 . One out of every three men and one out of every 12 women consume alcohol heavily (for men, over $80 \mathrm{~g}$ of ethanol in a typical drinking day, or either over $60 \mathrm{~g}$ every 3-4 days per week or over $40 \mathrm{~g}$ nearly every day; for women, these dose criteria were reduced by $25 \%$ ) (Webb et al, 2005). Over $90 \%$ of the male heavy alcohol users had consumed at least $80 \mathrm{~g}$ of ethanol in one day at least once per month in the past year.

About one-third of the Ukrainian population has experienced at least one mental disorder in their lifetime, diagnosable according to DSM-IV criteria. About one person in six (17.6\%) has experienced an episode in the past year, and $10.6 \%$ are diagnosed with a current disorder (Bromet et $a l, 2005)$. There is no gender difference in the overall prevalence rates, but the prevalence of individual diagnoses varies markedly by gender. The most common lifetime diagnoses among men are alcohol-related disorders (26.5\%). These comprise alcohol misuse without dependence (19.7\%) and alcohol misuse with dependence (6.7\%). In contrast, women more commonly experience mood disorders (20.8\%) and anxiety disorders (7.9\%) (Bromet et al, 2005).

\section{Historical perspective}

Official statistics for the incidence and prevalence of alcohol dependence in Ukraine from 1955 to 2007 are presented in Fig. 1. These data, as well as the stages of development of Ukrainian addiction services, correlate with the most important socio-economic and political changes in Ukraine (Bolotova et al, 2001).

The inexorable rise in rates of alcohol dependence from 1955 until 1971 reflects the active development of the addiction services, which were officially created by an Act of the Ministry of Health in 1959. It is interesting to note that before this Act was passed, there were only 40 beds and 8 offices for addiction treatment in the entire country. Due to the scarcity of beds and specialists, most patients with alcohol psychoses and non-psychotic forms of alcohol dependence were treated in general psychiatric hospitals. The Act led to the creation of the first addiction in-patient and out-patient departments and the growth of an addiction support network, as well as increases in the number of specialists in this field of psychiatry. An increase in the number of beds for the treatment of addictions was made possible, and these patients were predominantly treated for alcohol dependence (tobacco was not considered an addiction, and addictions to illegal drugs and medical drugs were rare).

During the period 1972-86, there was an exponential growth in the incidence and prevalence of alcohol dependence reported by official statistics. This period, the 'stagnation era' (zastoy) in the former Soviet Union, was associated with economic failure, long-term demoralisation and a declining quality of life and life expectancy. All these factors contributed to widespread alcoholism and crime (Laqueur, 1994). Addiction services implemented new, socially based methods for the prevention of binge drinking and alcoholism. During this period, cooperation between addiction services and the governmental, party, societal and institutional structures was introduced. Special commissions for the prevention of alcoholism and binge drinking 


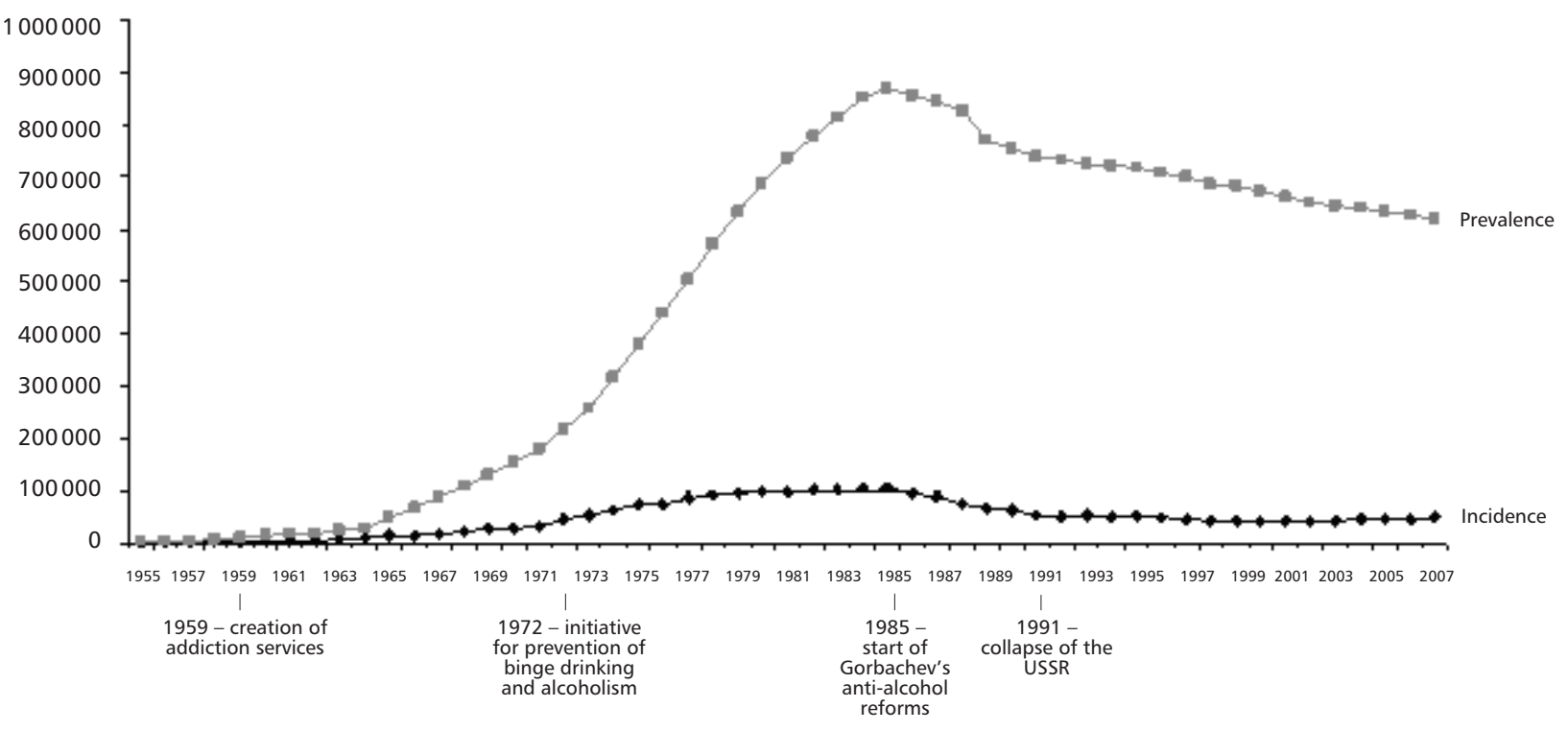

Fig. 1 Incidence and prevalence of alcohol dependence (AD, ICD-10 code F10.2) in Ukraine, 1955-2007 (Ministry of Health of Ukraine, unpublished data).

were created in large industrial enterprises and administrative establishments. These commissions assisted the coordination of governmental and societal institutions to control binge drinking and alcoholism. Addiction services were separated from mental health services. A legislative basis for compulsory treatment and 'vocational correction' was created, and this led to special labour institutions. The control of binge drinking became an important national task. Consequently, health providers lowered their thresholds for diagnosing alcohol use disorders. This change is reflected in the diagnoses assigned: the ratio of alcohol dependence to alcohol psychoses increased seven-fold, from 4.6 in 1968-71 to 32.2 in 1986.

Over 1986-89, there was a large decrease in the incidence and prevalence of alcohol dependence (Fig. 1) and alcohol psychoses, due to Gorbachev's anti-alcohol campaign, which, in spite of all criticisms, proved effective. The campaign started in May 1985; the prices of alcoholic beverages were raised, their sales were severely restricted, vineyards in the wine-producing republics were destroyed, the sale of alcohol in restaurants before 2 p.m. was prohibited, drinking in public places and alcohol advertising on television and in cinemas were banned, and people who were caught drunk in public were prosecuted.

During 1990-96, this anti-alcohol campaign was wound down, owing to its unpopularity among the population at large, as well as the inability of the Soviet Union's bureaucratic machine to continue running it; rates of alcohol psychoses then almost returned to what had been observed in 1984-85.

Global social and political changes in the country (notably the collapse of the Soviet Union in 1991, following ruination of industry and an economic crisis) have since led to a severe decrease in the capacity of the addiction services network in almost all regions of Ukraine. Former networks of cooperation, for all subdivisions of the addiction services, have been disrupted. The numbers of beds and staff have decreased. The organisation of addiction control has changed radically - the role of compulsory treatment, for example, has diminished, while anonymous forms of treatment and consultation have become much more popular.
Official statistics appear to show a gradual decrease in alcohol dependence (Fig. 1) and in alcohol psychoses since 1997. However, experts in the field of addiction believe that the official figures are misleading and that rates of alcohol dependence are actually increasing. They base their concerns on observed rates of alcohol-attributable morbidity and mortality, the decrease in life expectancy, negative demographic trends, and the high demand for addiction treatment since the collapse of the Soviet Union.

The fact that the official statistics are misleading could be attributable to a lack of epidemiological validity. The apparent gradual decrease in the incidence and prevalence of alcohol dependence may be explained by the incomplete restructuring of healthcare, coupled with financial and social instability. Consequently, medical services are no longer in a position to supply accurate data. There has been a breakdown of financing, disorganised and contradictory regulation of addiction services, and a lack of medication and equipment. Experts believe that social changes have also diversified the population of alcoholics. Some of them, mostly those with less severe dependence, have been able to change their drinking patterns to less harmful ones as a result of the new opportunities that the post-Soviet era has brought (e.g., owning businesses, self-realisation, increasing role of religion). Those with severe dependence have often died from alcohol-related disorders, an outcome that is supported by official statistics reporting an increase in alcohol-attributable mortality.

From 1990 (before the collapse of the USSR) to 2004 there was an increase in rates of acute alcohol intoxication of over 97\%; the figure was over $70 \%$ for alcohol-related disorders in general. Mortality due to alcohol psychoses and alcoholic liver cirrhosis increased 8- and 11-fold correspondingly (Fig. 2). In addition, the index of in-hospital mortality increased fourfold over Ukraine's first 15 years of independence.

\section{Service use}

An analysis of bed usage in specialised alcohol dependence care from 1990 to 2007 (unpublished data) reveals both 


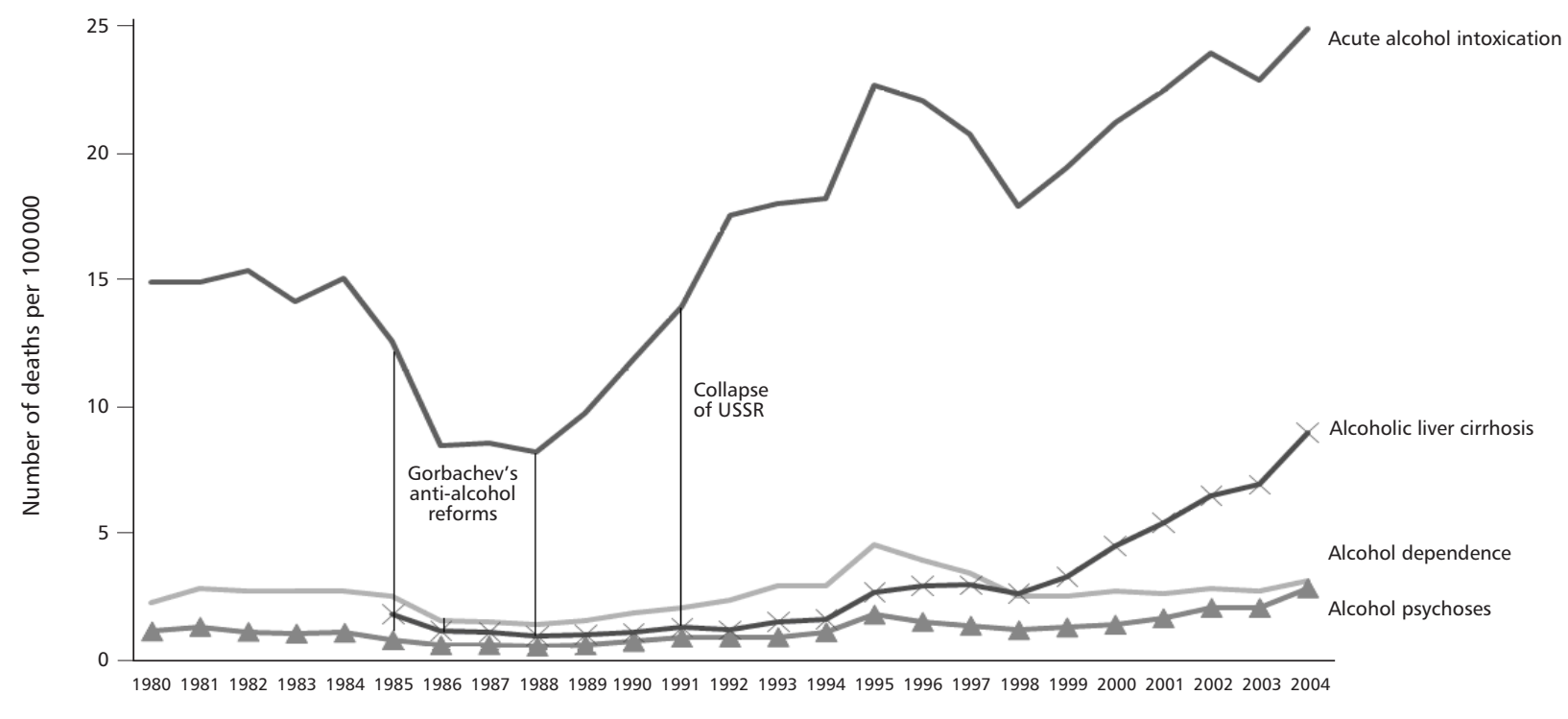

Fig. 2 Crude alcohol-attributable mortality rates per 100000 in Ukraine, 1980-2004 (Ministry of Health of Ukraine, unpublished data): acute alcohol intoxication (ICD-10 code F10.0); alcohol psychoses (ICD-10 code F10.5); alcohol dependence (ICD-10 code F10.2); alcoholic liver cirrhosis (data available only from 1985; ICD-10 code K70.3).

a reduction in the capacity of addiction services (due to budgetary problems) and high demand.

O There had been a decrease in the total number of dedicated beds $(-66 \%)$ as well as in the number of beds per 100000 population (-63\%).

O There had been a $26 \%$ increase in the active use of beds.

0 There had been an increase in the number of patients per hospital bed, per unit time, from 6.1 in 1994 to 22.4 in 2007 ( $+268 \%)$.

The length of stay in hospital had shortened by $66 \%$, from 46.1 days in 1990 to 15.8 days in 2007.

O There had been a $268 \%$ increase in mortality in hospitals.

It should be noted that some of the above changes (e.g. the decrease in the total number of hospital beds and the corresponding increase in the number of patients per bed) could also be partially explained by a shift in treatment practices from long-term to short-term in-patient treatment and from in-patient to out-patient treatment in general (as has been seen in North America and Western Europe). There were also some financial benefits for hospital administrations and physicians that favoured shorter patient stays and more intensive bed usage.

Overall, the number of hospital admissions for alcohol dependence increased by 24\%, from 110123 in 1990 to 136091 in 2007, which clearly demonstrates a high demand for addiction treatment, and these figures run counter to official statistics, which have consistently underreported the prevalence and incidence of alcohol dependence in Ukraine.

\section{Conclusions}

The rates of both alcohol consumption and alcohol use disorders have remained high in Ukraine for the past few decades. The official prevalence statistics depend heavily on the state of addiction services and socio-economic factors. Ukrainian addiction services have not yet recovered from the problems the country has experienced since 1991. Structural changes, better financing and staffing, and improved infrastructure and supply are needed to allow the health system to continue to meet the high demand for the effective treatment of addictions in contemporary Ukraine.

\section{References}

Bolotova, Z. N., Minko, O. I., Artemchuk, A. F., et al (2001) Major stages of the creation and development of addiction services for the population of Ukraine (1959-2000). Arkhiv Psykhiatrii, 4, 129-135.

Bromet, E. J., Gluzman, S., Paniotto, V., et al (2005) Epidemiology of psychiatric disorders in Ukraine: findings from the Ukraine Mental Health Survey. Social Psychiatry and Psychiatric Epidemiology, 40, 689-690.

Degenhardt, L., Chiu, W. T., Sampson, N., et al (2008) Toward a global view of alcohol, tobacco, cannabis, and cocaine use: findings from the WHO World Mental Health Surveys. PLoS Medicine, 5, e141 DOl: 10.1371/journal.pmed.0050141.

Laqueur, W. (1994) The Dream That Failed: Reflections on the Soviet Union. Oxford University Press.

Popova, S., Rehm, J., Patra, J., et al (2007) Comparing alcohol consumption in Central and Eastern Europe to Southern and Western Europe, Russia and Ukraine. Alcohol and Alcoholism, 42, 465-473.

Voloshin, P. V., Linskiy, I. V., Minko, O. I., et al (2003) State of narcological health in the population of Ukraine and activities of addiction services in 2002. Ukrainskiy Visnik Psykhonevrologii, 2, 5-6.

Webb, C. P. M., Bromet, E., Gluzman, S., et al (2005) Epidemiology of heavy alcohol use in Ukraine: findings from the World Mental Health Survey. Alcohol and Alcoholism, 40, 327-335.

WHO World Mental Health Survey Consortium (2004) Prevalence, severity, and unmet need for treatment of mental disorders in the World Health Organization World Mental Health Surveys. JAMA, 291, 2581-2590.

Launch of the RCPsych Awards 2009 - celebrating excellence in psychiatry

The RCPsych Awards have been designed to recognise the very best practice within psychiatry today. More information, application forms, category criteria and rules of entry can be downloaded from:

http://www.rcpsych.ac.uk/members/currentissues/ rcpsychawards.aspx

or can be obtained by email from Nicola Boyce at nboyce@rcpsych.ac.uk. 